\title{
Residência multiprofissional tecendo práticas interdisciplinares na prevenção da violência
}

\author{
Weaving inter-disciplinarity practices into the avoidance \\ of violence in the multi-professional residence
}

Ana Amélia Nascimento da Silva Bones ${ }^{1}$, Silvio César Cazella¹, Lara Susane Weber²,

Maira Rafaela Röhrig da Costa², Márcia Pereira Saraiva², Marina Ramos Bopsin²

'Universidade Federal de Ciências da Saúde de Porto Alegre (UFCSPA) - Porto Alegre (RS), Brasil.

${ }^{2}$ Programa de Residência Integrada Multiprofissional em Saúde da Criança, Hospital Materno-Infantil Presidente Vargas (HMIPV) - Porto Alegre (SP), Brasil.

DOI:http://dx.doi.org/10.7322/abcshs.v40i3.819

\section{RESUMO}

Introdução: A complexidade da atenção às situações de violência requer o investimento na integralidade das ações e do cuidado, lançando às equipes multiprofissionais o desafio da construção de uma prática interdisciplinar em conjunto com a escola. Relato de experiência: Analisar a integralidade da atenção à saúde e à educação a partir da ação das residentes do Programa da Residência Integrada Multiprofissional em Saúde da Criança com transversalidade em violências e vulnerabilidades inseridas numa equipe de Estratégia de Saúde da Família no Município de Porto Alegre e na escola estadual pertencente ao seu território. Trata-se da experiência interdisciplinar desenvolvida em dois níveis de abordagem: com os alunos do $1^{\circ}$ ao $4^{\circ}$ ano através de atividades lúdicas; e com os pais e responsáveis através da roda de conversa. A base da intervenção foram as oficinas com os alunos, buscando problematizar, através de intervenções lúdicas e brincadeiras, as situações de violência percebidas nos seus diversos ambientes. Conclusão: A prática interdisciplinar de forma consciente permite a organização do processo de trabalho com o escopo da prática colaborativa em projeto de educação interprofissional.

Palavras-chave: violência, criança; relações interprofissionais.

\section{ABSTRACT}

Introduction: The complexity of the attention to the situations of violence requires the investment in actions and care integrity, launching to the multi-professional teams the challenge of building an interdisciplinary practice together with the school. Experience report: To analyze the integrity of the attention to health and education of the residents' actions in the Program of the Multi-professional Integrated Residence in Children's Health, which are exposed to violence and vulnerability and inserted into a team of Family Health Strategy in Porto Alegre District, and the Public School that belongs to its area. It works on the inter-course studying experience developed inside two approaching levels: one with the primary level children through playing activities, and the other with their parents or guardians through conversations. The support for this intervention was the workshops with the students, aiming at bringing down the violent situations in their different environments through playing games. Conclusion: The interdisciplinary practice in a conscious way allows the organization of the work process with the scope of the collaborative practice in one inter-professional education project.

Keywords: violence; child; inter-professional relations. 


\section{INTRODUÇÃO}

O Sistema Único de Saúde (SUS) é proveniente de uma grande reivindicação que se deu a partir do envolvimento da sociedade civil, através de movimentos sociais que desencadearam marco histórico. Simultaneamente a esse movimento, o Estatuto da Criança e do Adolescente se constituiu de forma similar. Esses dois símbolos de conquistas de direitos humanos ressignificaram os modos de organização dos serviços e das práticas de cuidado, entendendo que a saúde torna-se um direito do cidadão e dever do Estado, e a criança passa a ser considerada sujeito de direitos. Dessa forma, observando que ambos tiveram início há 25 anos, sua implementação pode ser considerada uma construção recente e cada nova ação, proposta no campo da saúde e da proteção, um desafio.

A abordagem da temática da violência contempla um dos princípios do SUS: a integralidade do cuidado. Nesse contexto, conjectura-se o olhar ampliado sobre o processo de saúde-doença, considerando e compreendendo a dinâmica dos determinantes sociais e os demais aspectos que incidem sobre a vida dos sujeitos. É necessário compreender que a saúde e a doença formam um contínuo, em que se relacionam os aspectos econômicos, socioculturais, experiência pessoal e estilos de vida do ser humano ${ }^{1}$.

A organização do processo de trabalho inclui tecnologias em saúde que visam a complexidade dos objetos de intervenção e a intersubjetividade $^{2}$. Para tanto, o SUS também se torna responsável pela formação de recursos humanos. Conforme Ceccim e Feuerwerker ${ }^{3}$, a formação centrada no contexto da saúde deveria objetivar a transformação das práticas profissionais e da organização do trabalho, buscando problematizar os processos de trabalho e potencializar o cuidado em saúde das pessoas, populações e coletivos. Em consonância a isso, a Organização Mundial de Saúde (OMS) publica em 2010 o Marco para Ação em Educação Interprofissional e Prática Colaborativa, evidenciando a educação como mecanismo que viabiliza a transformação da prática no contexto local resultando serviços de excelência em saúde 4 .

Nesse sentido, as Residências Multiprofissionais em Saúde, instituídas nos âmbitos dos Ministérios da Saúde e da Educação através da promulgação da Lei no 11.129 de $2005^{5}$, têm como objetivo a formação em serviço. Considerando a promulgação dessa lei, nos últimos anos houve uma ampliação dos programas de residência multiprofissional. Dessa forma, a Prefeitura Municipal de Porto Alegre em parceria com Universidade Federal do Rio Grande do Sul constituem em 2014 o Programa de Residência Integrada Multiprofissional em Saúde da Criança (PRIMSC) com Transversalidade em Violência e Vulnerabilidade. O propósito do PRIMSC é de articular redes de intervenção entre os diversos setores, integrando ações e estratégias na área de saúde da criança, frente às questões de violência e vulnerabilidades, tendo em vista os princípios da educação permanente em saúde.

Dentre os diversos campos de atuação propostos pelo programa de residência, a Estratégia de Saúde da Família (ESF) é inserida nesse processo e surge como base para a reorganização da atenção primária em saúde no Brasil, em consonância com as diretrizes da Política Nacional da Atenção Básica ${ }^{6}$. Fundamenta-se no trabalho de equipes multiprofissionais em uma área adscrita, desenvolvendo ações de saúde a partir do conhecimento da realidade do território, com suas próprias prioridades de ação, potencialidades e limitações ${ }^{7}$.

No âmbito escolar, o Programa Saúde na Escola (PSE) se configura como importante espaço para articulação das equipes de atenção primária com os profissionais de educação, sendo uma política intersetorial entre Ministério da Saúde e Ministério da Educação ${ }^{8}$. As articulações do PSE devem propiciar a sustentabilidade das ações a partir da conformação de rede de corresponsabilidade entre os serviços que são ofertados no território, criando espaços de prevenção e promoção de saúde no ambiente escolar. Dessa forma, o PSE visa fomentar uma gestão coletiva e participativa entre os profissionais, os educandos e a comunidade, proporcionando o protagonismo desses atores no próprio processo de produção de saúde.

Através da formação em serviço na área da saúde da criança propiciam-se, nos diversos níveis da atenção, habilidades para ações em saúde frente às questões de violência e vulnerabilidades. Pautada na complexidade das relações humanas e no modo organizativo da sociedade, esta proposta busca o desenvolvimento de competências que objetivam formar um perfil profissional mais comprometido com o ser humano. A violência, entendida e assumida como um fenômeno mundial, democrático, multicausal, multifacetado e multisetorial presente na sociedade contemporânea, torna-se um problema de saúde pública. Nesse sentido, a questão da violência requer um olhar ampliado e integralizado sobre a vida do sujeito, que ultrapasse as barreiras de ações multiprofissionais, trazendo para a prática cotidiana do profissional o desafio de ações interdisciplinares.

A multidisciplinaridade como primeiro nível de agrupamentos de disciplinas em contato pressupõe uma gama diversificada das mesmas, porém não articuladas entre si de forma cooperativa, o que não significa a inexistência de relações, ocorrendo de fato a automatização e a fragmentação das ações profissionais ${ }^{9}$. Iribarry ${ }^{9}$ aponta a interdisciplinaridade como um passo além do fazer multiprofissional, onde há a interação das disciplinas em dois níveis hierarquizados, sendo o nível superior o coordenador e integrador das disciplinas, em busca de um objetivo comum. Portanto, uma discussão acerca do termo interdisciplinaridade pressupõe novas formas de relacionamento, onde o coordenador assume o papel de administração e tomada de decisões, após o processo de interação entre as demais áreas profissionais.

Brinhosa $^{10}$ refere que a interdisciplinaridade realiza a interpenetração entre as áreas, permitindo o diálogo entre os saberes capazes de redimensionar a prática, entendendo o problema a partir de cada olhar, para uma tomada de decisões e execução de propostas inerentes aos campos envolvidos, a partir da centralização do todo. A interdisciplinaridade não nega o aprofundamento das áreas de conhecimento, mas realiza uma crítica quando aponta que a fragmentação das disciplinas impossibilita realizar 
ações resolutivas que respondam às situações-problema no cotidiano da vida humana.

Nessa perspectiva, a prática interdisciplinar, ao trabalhar o tema da violência na interface entre saúde e educação no PSE, constitui um desafio que será abordado neste relato de experiência da residência multiprofissional no desenvolvimento de um projeto interdisciplinar.

\section{RELATO DE EXPERIÊNCIA}

O presente relato de caso traz a experiência de um dos campos de prática da residência supracitada, e suas intervenções junto ao PSE em uma escola pública na região central de Porto Alegre, Rio Grande do Sul, no período de agosto a outubro de 2014. A proposta de ação surgiu por meio da demanda apresentada por ambos os serviços (saúde e educação), referente à necessidade de dialogar sobre a temática da violência com os alunos das séries iniciais $\left(1^{\circ}\right.$ ao $4^{\circ}$ ano, com intervalo de idade entre 6 e 12 anos), em 4 diferentes momentos, bem como a realização de ações que integrassem a participação dos pais/responsáveis no enfrentamento desses conflitos. Os referidos serviços referiram que as turmas das séries iniciais apresentavam comportamentos agressivos, verbalizavam ofensas e as brigas aconteciam com frequência, além de ser restrito o diálogo entre alunos, dificultando a resolução de conflitos. O convite para participação do PSE, mediante autorização, foi feito a todos os alunos das séries iniciais e seus responsáveis. Participaram das atividades 70 crianças e 14 pais/responsáveis no espaço de roda de conversa.

Para a elaboração de uma proposta de trabalho buscou-se inicialmente realizar o diagnóstico do território, que ocorreu através do reconhecimento do local e contato com a comunidade, com o intuito de planejar estratégias de trabalho direcionadas às demandas do público alvo. A percepção foi que o território apresenta as vulnerabilidades de grandes centros urbanos com população marginalizada, a mercê de atividades informais e por vezes ilícitas.

As ações aqui relatadas foram realizadas pela primeira equipe de Residência Multiprofissional da PRIMSC (Psicologia, Fonoaudiologia, Serviço Social e Nutrição). Contudo, a proposta de abordagem foi de uma ação interdisciplinar e não multidisciplinar, no trabalho de rede com escola e ESF. Por conseguinte, as possibilidades de intervenção foram pensadas prioritariamente a partir do conceito de campo, por meio da interface com o trabalho do preceptor (nesse caso, uma médica) e com os demais profissionais da rede.

A intervenção propôs um olhar acolhedor para a realidade dessa população e uma aproximação com suas características. Sendo assim, no primeiro momento, o objetivo foi realizar oficinas com as crianças, buscando problematizar, através de intervenções lúdicas e brincadeiras, situações de violência vivenciadas e praticadas nos seus diversos ambientes. Após essa etapa, buscou-se colocar em foco a discussão dos relacionamentos interpessoais; as possibilidades de lidar com as situações de conflitos; relação intimista e com o outro; a introjeção de normas sociais; e a compreensão das possíveis diferentes violências que ocorrem no cotidiano das crianças em diversos espaços. No segundo momento, o objetivo foi abordar as questões levantadas pelas crianças, a fim de realizar um diálogo com os responsáveis pelas crianças através da proposta de uma roda de conversa.

As oficinas realizadas com as crianças buscaram oferecer um espaço de diálogo através de intervenções lúdicas, discutindo sobre as situações de violência vivenciadas nos seus ambientes. O propósito das atividades foi fazer com que a palavra circulasse entre todos, criando um espaço acolhedor onde foi possível que as crianças articulassem por meio da narrativa de experiências as situações incompreensíveis que vivenciavam ${ }^{11}$. Nesses encontros, foi possível observar as relações que se estabelecem nesse ambiente escolar. Durante as atividades, houve diversos momentos de agressões físicas e verbais, expressadas pelas crianças em situações de impasses. Algumas brincadeiras também indicaram encenações que simulavam situações de conflitos e violência.

Assim, procurou-se identificar qual o tipo mais comum de violência nominada pelas crianças e disparar falas sobre os sentimentos que essas situações despertaram ${ }^{8}$. Além disso, questionou-se sobre quais as figuras de referência para auxílio quando alguma situação ocorre, buscando identificar uma rede de apoio, e o que é possível fazer para prevenir a violência.

A partir da análise das respostas, percebeu-se que as crianças identificaram diversas situações violentas, em diferentes contextos (na escola, em casa, na rua). Entre as situações vivenciadas, muitas referiram conflitos no ambiente escolar, indicando agressões físicas e verbais. Outras são referentes a castigos físicos, impostos no núcleo familiar, além de diversas situações de violência presenciadas no contexto da comunidade.

A partir das respostas indicadas por meio das questões disparadoras, as crianças relatam que no núcleo familiar prevalecem situações de agressões físicas entre irmãos e agressões verbais em relação aos pais. Quanto às situações de violência presenciadas no contexto da comunidade, os relatos indicam a presença do tráfico de drogas, do uso de armas de fogo, de brigas com facas, de histórias de assassinatos e estupro. As crianças mencionam práticas de agressões físicas entre colegas e irmãos, além de agressões verbais direcionadas a professores e familiares, indicando o uso de palavras e expressões pejorativas.

No que se refere aos sentimentos despertados ao sofrer ou executar uma ação violenta, a maioria mencionou desconforto. Quando questionados sobre a quem recorrem quando são vítimas de violência, indicaram as figuras dos pais e, no contexto escolar, os professores. Sobre o que é possível fazer para prevenir a violência, as crianças referiram à importância do diálogo e do uso das "palavrinhas mágicas" (por favor, obrigado, com licença, desculpe), como forma de articulação nos espaços de convívio social.

O trabalho realizado com as crianças foi apresentado aos pais e responsáveis, a partir de um espaço de roda de conversa. Os participantes foram identificando comportamentos dos filhos, 
relatando como lidavam com as situações de conflitos intrafamiliar. Também trouxeram questões em relação à postura e papel da escola nessas situações, relatando pontos positivos e negativos em relação às decisões e atitudes tomadas. A partir dos relatos, os participantes reconheceram suas dificuldades em lidar com essas situações frente à realidade do contexto violento em que vivem.

A participação ativa dos responsáveis na roda de conversa, expondo suas percepções sobre a violência no contexto local, e a solicitação de novas intervenções do serviço no ambiente escolar permitem avaliar positivamente essa experiência. Dessa forma, fomenta-se um olhar especial para a criança, considerando o contexto em que vive, e o desenvolvimento de estratégias para melhor intervir em conflitos familiares e dentro da escola na qual a criança está envolvida.

\section{DISCUSSÃO}

A prática interdisciplinar coloca-se como potencializadora da integração que possibilita uma compreensão ampliada do objeto de trabalho em saúde, por meio da interação entre os profissionais e a articulação entre os diversos saberes e fazeres presentes no trabalho em saúde, possibilitando, deste modo, outras formas de relação entre os sujeitos envolvidos no processo ${ }^{9,10,12}$. Japiassu ${ }^{13}$ indica que a multidisciplinaridade se referencia à justaposição de várias disciplinas (nesse caso, profissões), sem a exigência de um trabalho em equipe e coordenado, o que a diferencia da interdisciplinaridade, a qual se refere à solidariedade e compartilhamento de conhecimento e à preocupação do profissional em contribuir com o seu saber objetivando a resolução de um problema ${ }^{14}$.

Nesse contexto, a interdisciplinaridade entrou como eixo norteador das ações em saúde, com a proposta de envolver vários segmentos da sociedade, possibilitando o diálogo e a construção de saberes e práticas que pautam o fortalecimento no que concerne a consolidação das práticas de promoção da saúde e resolubilidade do sistema ${ }^{1}$. Esse foi o modo de trabalho encontrado que possibilitou integrar os diversos saberes da escola, da ESF e da comunidade com a residência multiprofissional, na proposta de trabalhar com crianças e familiares sobre a questão da violência, entendendo que esses atores estão inseridos em um contexto de vulnerabilidade.

Entende-se que a violência é polifórmica, multifacetada e encontra-se diluída na sociedade por meio das mais diversas manifestações, que se interligam, interagem, (re)alimentam-se e se fortalecem ${ }^{15}$. Dessa forma, as intervenções com as turmas tiveram como intuito dialogar sobre relacionamento interpessoal, constituição de vínculos, e reconhecimento de situações de violência vivenciadas ou praticadas.

Considerando que a temática da violência é um assunto complexo e pouco trabalhado, a proposta buscou propiciar momentos a partir da fala e do brincar, com uma linguagem de fácil entendimento, que estimulasse a participação das crianças. Abordar o tema da violência significa romper com o pacto de silêncio que a cerca, buscando desenvolver estratégias individuais e coletivas de enfrentamento diante dessa realidade. Trata-se, portanto, de ações de promoção em saúde, que visam ampliar o acesso das crianças e familiares a recursos que possibilitem maior autonomia, bem como criar novas formas para lidar com as diferentes situações que ocorrem em seu cotidiano.

Assim, foi averiguada a relevância de poder articular as ações com os pais e familiares das crianças. Ou seja, colocar em roda o tema da violência, em espaços onde os diferentes atores que compõem essa realidade possam falar sobre sua percepção em relação ao assunto, sendo acolhidos sem preconceito ou culpabilização. Culpabilização essa que é percebida de forma velada, mesmo que os responsáveis também se encontrem na situação de vítimas da violência e que sua rede de enfrentamento seja frágil e, muitas vezes, oculta.

Por meio da experiência do PSE, percebe-se que há um contexto de violência estrutural ${ }^{15}$, onde muitos sujeitos vivem a exclusão social e se encontram em desamparo. A essa realidade somam-se situações violentas advindas do tráfico de drogas e de disputas de poder. Resultam dessa soma de fatores situações como: abandono, trabalho infantil, negligência, evasão escolar, entre outras.

Entende-se que o território é resultado de uma acumulação de fatores históricos, sociais e ambientais que interferem nos processos de saúde-doença ${ }^{7}$. Assim, diante da gama de singularidades de um contexto territorial, percebe-se a importância do movimento de ir ao território, conhecê-lo, desbravá-lo e observá-lo, para que então sejam pensadas estratégias de atenção à comunidade.

É importante compreender que a busca de estratégias pautadas nos princípios interdisciplinares e intersetoriais favorecem a interlocução entre a população e o poder público, dentro de uma perspectiva para o desenvolvimento e exercício da cidadania e do controle social. As ações desenvolvidas buscaram integrar diferentes saberes a partir de espaços de diálogo que envolveram os diversos atores sociais que atuam nessa realidade (profissionais de saúde, profissionais de educação, pais/familiares/cuidadores e as crianças). Confirma-se o potencial para a realização de propostas que visam beneficiar os usuários e trabalhadores, assim como uma reorganização no modo de fazer assistência à saúde, a partir dos microespaços de trabalho ${ }^{12}$.

A violência ocupa lugar de destaque na sociedade moderna e configura-se como um problema de saúde pública. A promoção de ações para a sua prevenção em público infantil requer atividades apropriadas para a faixa etária, articuladas com o território e serviços de educação e saúde. A proposta do PRIMSC, mesmo sendo na sua formação original uma residência multiprofissional, permite atuar conscientemente de modo interdisciplinar no seu campo de estágio a fim de integrar diversos pontos da rede de assistência no PSE. Assim, a escolha da organização do processo de trabalho contribui para auxiliar na definição dos papéis dos integrantes, seus objetivos e relações conforme o escopo das práticas colaborativas em projetos de educação interprofissional para a excelência em serviços de saúde. 


\section{REFERÊNCIAS}

1. Cardoso JP, Vilela ABA, Souza NR, Vasconcelos CCO, Caricchio GMN. Formação interdisciplinar: efetivando propostas de promoção da saúde no SUS. RBPS 2007;20(4):252-58. http://dx.doi.org/10.5020/18061230.2007.p252

2. Borges MJL, Sampaio AS, Gurgel IGD. Trabalho em equipe e interdisciplinaridade: desafios para a efetivação da integralidade na assistência ambulatorial às pessoas vivendo com HIV/Aids em Pernambuco. Ciênc Saúde Coletiva. 2012;17(1):147-56. http://dx.doi.org/10.1590/S1413-81232012000100017

3. Ceccim RB, Feuerwerker LCM. O quadrilátero da formação para a área da saúde: ensino, gestão, atenção e controle social. Physis. 2004;14(1):41-65.

4. Organização Mundial da Saúde. Departamento de Recursos Humanos para a Saúde. Marco para Ação em Educação Interprofissional e Prática Colaborativa. Genebra: 2010.

5. Brasil. Coordenação de Estudos Legislativos (CEDI) [internet]. Lei $n^{\circ} 11.129$ de 30 de junho de 2005. Institui o Programa Nacional de Inclusão de Jovens - ProJovem; cria o Conselho Nacional da Juventude - CNJ e a Secretaria Nacional de Juventude; altera as Leis ns. 10.683, de 28 de maio de 2003, e10.429, de 24 de abril de 2002; e dá outras providências. Disponível em: http://www.camara. gov.br/sileg/integras/554841.pdf. Acesso em: 16 jul. 2015

6. Brasil. Ministério da Saúde. Portaria $n^{\circ} 2.488$, de 21 de outubro de 2011. Aprova a Política Nacional de Atenção Básica, estabelecendo a revisão de diretrizes e normas para a organização da Atenção Básica, para a Estratégia Saúde da Família (ESF) e o Programa de Agentes Comunitários de Saúde (PACS). Disponível em: http://bvsms. saude.gov.br/bvs/saudelegis/gm/2011/prt2488_21_10_2011.html. Acesso em: 16 jul. 2015
7. Akerman M, Campos GWS, Minayo MCS, Carvalho YM, Drumond Junior M. Tratado de Saúde Coletiva. In: Andrade LOM, Bueno $\mathrm{ICHC}$, Bezerra RC. Atenção Primária à Saúde e Estratégia Saúde da Família. São Paulo: Hucitec; 2012. p.845-902.

8. Brasil. Ministério da Saúde. Ministério da Educação. Guia de sugestões de atividades Semana Saúde na Escola 2014. Brasília: 2014.

9. Iribarry IN. Aproximações sobre a transdisciplinaridade: algumas linhas históricas, fundamentos e princípios aplicados ao trabalho em equipe. Psicol Reflex Crít. 2003;16(3):483-90. http://dx.doi.org/10.1590/S0102-79722003000300007

10. Brinhosa MC. Interdisciplinaridade: possibilidades e equívocos. Acta Fisiátr. 1998;5(3):164-69.

11. Milman L. Casa da árvore: a ética de Françoise Dolto nas favelas cariocas. Pulsional Rev Psicanál. 2005;17(181):46-53.

12. Matos E, Pires DEP, Campos GWS. Relações de trabalho em equipes interdisciplinares: contribuições para a constituição de novas formas de organização do trabalho em saúde. Rev Bras Enferm. 2009;62(6):863-9. http://dx.doi.org/10.1590/S0034-71672009000600010

13. Japiassu $H$. Interdisciplinaridade e patologias do saber. Rio de Janeiro: Imago; 1976

14. Raxach JC. Reflexões sobre assistência à Aids: relação médico-paciente, interdisciplinaridade, integralidade. In: Pinheiro R. A importância do SUS: o político, o social e as questões a superar. Rio de Janeiro: ABIA; 2003; p.59-61.

15. Cruz Neto O, Moreira MR. A concretização de políticas públicas em direção à prevenção da violência estrutural. Ciênc Saúde Coletiva. 1999;4(1):33-52. 